\title{
Non-Selective Toxicological Effects of the Insect Juvenile Hormone Analogue Methoprene. A Membrane Biophysical Approach
}

\author{
João P. Monteiro • Romeu A. Videira • \\ Manuel J. Matos • Augusto M. Dinis • Amália S. Jurado
}

Received: 13 September 2007 / Accepted: 7 December 2007 /

Published online: 31 January 2008

(C) Humana Press Inc. 2008

\begin{abstract}
The Gram-positive bacterium, Bacillus stearothermophilus, was used as a model organism to identify the non-selective toxic effects of the currently used insecticide methoprene (isopropyl(2E,4E)-11-methoxy-3,7,11-trimethyl-2,4-dodecadienoate). A significant decrease of the yield of bacterial cultures and a premature appearance of ultrastructural abnormalities in cells cultured in the presence of the insecticide were taken as indicators of cytotoxicity. A putative correlation of this cytotoxicity with methoprene-induced perturbations on membrane lipid organization was investigated, using differential scanning calorimetry and the fluorescence polarization of 1,6-diphenyl-1,3,5-hexatriene (DPH) and its propionic acid derivative (DPH-PA). The membrane physical effects depended on the lipid bilayer composition and packing. The most striking effect was a progressive broadening and shifting to lower temperatures, with increasing methoprene concentrations, of the main transition phase of the dimyristoyl- or dipalmitoylphosphatidylcholine bilayers and of the lateral phase separation of liposomes reconstituted with the lipid extracts of $B$. stearothermophilus.
\end{abstract}

Keywords Methoprene - Lipid dynamics · Differential scanning calorimetry · Fluorescence polarization $\cdot$ Cell ultrastructure $\cdot$ Bacillus stearothermophilus

J. P. Monteiro $\cdot$ M. J. Matos $\cdot$ A. S. Jurado

Centro de Neurociências e Biologia Celular; Department of Biochemistry, University of Coimbra, 3001-401 Coimbra, Portugal

R. A. Videira

Higher School of Technology, Polytechnic Institute of Viseu, 3504-510 Viseu, Portugal

A. M. Dinis

Laboratório de Microscopia Electrónica, Department of Botany, University of Coimbra, 3001-401 Coimbra, Portugal

A. S. Jurado $(\square)$

Department of Biochemistry, University of Coimbra, Apartado 3126, 3001-401 Coimbra, Portugal e-mail: asjurado@ci.uc.pt 